\title{
The Production of /P, T, K/ among Heritage SPEAKERS OF SPANISH IN THE UNITEd StateS
}

Oihane Muxika Loitzate

The present study explores whether heritage speakers of Spanish in the United States pronounce voiceless stops $(/ \mathrm{p}, \mathrm{t}, \mathrm{k} /)$ differently in cognate words and non-cognate words in Spanish and in English depending on their degree of dominance in both languages. The acoustic measurement used to determine whether $/ \mathrm{p}, \mathrm{t}, \mathrm{k}$ / are pronounced differently or not is the Voice Onset Time (or VOT), which is longer for word initial /p, t, k/ in English whereas it is shorter in Spanish (Lisker \& Abramson, 1964). This study analyzes the production data of 8 heritage speakers who completed the Bilingual Language Profile (or BLP) Questionnaire (Birdsong et al., 2012), a read-aloud task, and a follow-up interview. The results show that informants pronounce /p, t, k/ differently in English and in Spanish. Moreover, informants' linguistic dominance influences their production of voiceless stops in English, but not as much in Spanish. A closer look at the data shows that informants' language proficiency could be influencing their pronunciation of $/ \mathrm{p}, \mathrm{t}, \mathrm{k} /$ in Spanish. Furthermore, this study shows that there is an overall effect of cognate words in the production of voiceless stops in Spanish and English. The current study is of interest because it focuses on heritage speakers' phonemic inventories, an understudied area of linguistics (Rao \& Ronquest, 2015; Kim, 2018) and it combines the BLP Questionnaire and the follow-up interview

OiHANe MUXIKA LOITZATE,

Instituto de Lengua y Cultura Españolas (ILCE), Universidad de Navarra e-mail:omuxikal@unav.es 
to retrieve information about heritage speakers' degree of bilingualism and linguistic attitudes. This methodology allows to explore how sociolinguistic attributes influence heritage speakers' pronunciation.

KEYWORDS: heritage speakers, stops, voice onset time, cognates.

\section{INTRODUCTION}

The present study analyzes the production of voiceless stops (/p, t, k/) among heritage speakers of Spanish living in the United States. More precisely, it explores whether heritage speakers' degree of language dominance has an effect on their production of cognates and non-cognates with word initial /p, t, k/ in Spanish and English. This study measures the Voice Onset Time or VOT (Ladefoged \& Johnson, 2014, p. 126), which is shorter in Spanish than in aspirated /p, t, k/ in English (Lisker \& Abramson, 1964). In the context of bilingual speakers, VOT values that are shorter are seen as "more Spanish-like", whereas VOT values that are longer are seen as "more English-like" (Amengual, 2012, p. 519). Overall, the current study is of interest because it focuses on the production of speakers who are proficient in English as well as in Spanish, their heritage language. This study retrieves data from both English and Spanish in order to compare heritage speakers' production to each other's. Following this methodology, the present study avoids comparing heritage speakers to monolingual speakers and it moves away from the idea of "incomplete acquisition", which is problematic (Otheguy, 2013; Pascual y Cabo \& Rothman, 2012).

Previous studies have highlighted the benefits of using cognate words in Spanish and English to facilitate learning of vocabulary in a second language (L2) (Montelongo, Hernández, \& Herter, 2011). Moreover, there are studies that have explored the effects that cognate words have in pronunciation (Brown \& Harper, 2009; Flege, Frieda, Walley, \& Randazza, 1998; Amengual, 2012). According to Flege et al. (1998) analyzing cognates can shed some light on our understanding of how the bilingual lexicon is organized (p. 158). More precisely, according to Amengual (2012), the results arising from studies on cognate words are able to show whether bilinguals' two linguistic systems are activated when they are speaking a language or not (p. 526). As in Flege et al. 
(1998) and Amengual (2012), the present study focuses on the VOT when speakers pronounce cognate words and non-cognate words. As in Amengual (2012), informants in this study complete a read-aloud task in which the sentences are presented using transition times to control for differences in speech rate and to ensure that this does not affect the VOT. Moreover, this study expands on previous ones as it explores the VOT of the three voiceless stops in Spanish and in English.

Overall, this study adds to previous analyses of heritage speakers' production of /p, t, k/ (Kim, 2011; Perara-Lunde, Lindsey, \& File Muriel, 2016; Amengual, 2012) because it combines quantitative data from the Bilingual Language Profile (or BLP) Questionnaire (Birdsong, Gertken, Amengual, 2012; Gertken, Amengual, Birdsong, 2014) and qualitative data from a follow-up interview. This allows to explore how heritage speakers' linguistic dominance and attitudes correlate with their pronunciation, an aspect that has not been analyzed in detail by previous studies (Rao \& Ronquest, 2015).

\section{Heritage Speakers of Spanish in the United States}

The United States Census Bureau estimates that there were 325,719,178 inhabitants in the U.S. in July 2017, and $18.1 \%$ of them were Hispanic or Latino. Many of them can speak Spanish, and according to Lipski (2008), speakers of Spanish in the U.S. represent one of the fastest-growing language minorities in the country (p. 1). Lopez and Gonzalez-Barrera (2013) reported that the number of Spanish speakers in the U.S. grew from 11 million in 1980 to more than 37 million in 2013 due to immigration and the growth of the Hispanic and Latino population in the United States. The number of Spanish speakers in the U.S has continued increasing and the U.S. has become the country with the second-largest Spanish-speaking population in the world.

Despite the growth of Spanish speakers in the U.S., the number of Spanish speaking parents who speak Spanish to their children has decreased (Pew Hispanic Center, 2018). According to Beaudrie, Ducar, and Potowski (2014), this decrease can be understood more clearly if one looks at the status of English and compares it to the status of Spanish in the country. Beaudrie et al. (2014) claim that people associate English with power, whereas they tend to make negative associations between the Spanish language and poverty, crime, and immigration. For that reason, many immigrants and their children are 
exposed to ideologies that prioritize the use of English and undervalue Spanish (Beaudrie et al., 2014). Consequently, immigrants' children (second generation) and grandchildren (third generation) teach less Spanish to their descendants than foreign-born parents (Lopez, Krogstad, \& Flores, 2018).

When second, third or later generations learn Spanish, they are frequently referred to as 'heritage learners' or 'heritage speakers' of the language. The present study adopts the narrow definition of the term 'heritage learner' and focuses on the production data of individuals who learned Spanish as a heritage language through their families and communities and who have some proficiency in it (Benmamoun, Montrul, \& Polinsky, 2013; Beaudrie et al., 2014). As this study analyzes the data of individuals who can already communicate in Spanish and who may not be taking Spanish classes, I use the term 'heritage speaker' instead of 'heritage language learner' to refer to them (Benmamoun et al., 2013, p. 287). Moreover, in this study, the term 'heritage language' will be used to refer to the different varieties of Spanish spoken by heritage speakers.

This study focuses on heritage speakers' production data in English and in Spanish (their heritage language), and avoids comparing their production to that of L2 learners or monolingual speakers of Spanish. According to Rao (2019), previous studies on the phonology of heritage speakers of Spanish have focused on the effects of different variables on their perception and production in Spanish and the differences between these variables when comparing heritage speakers to monolingual speakers and to speakers of Spanish who migrated to the U.S. later in life (p. 439). This study avoids comparing heritage speakers' sound inventory to that of L2 learners or monolingual speakers because they differ from each other in several aspects and this could affect the validity of the results drawn from such comparisons. First of all, heritage speakers differ from L2 learners in that they learn their heritage language through their families or communities, whereas L2s are often times learned in an academic setting. Besides differing in the learning context, heritage speakers can also differ from L2 learners in their age of acquisition of the language, the language variety that they learned, their connection to the language and its associated culture, and their proficiency (Beaudrie et al., 2014).

Heritage speakers' varieties of Spanish in the U.S. also differ from the varieties spoken by monolingual speakers of Spanish. Often times monolingual speakers have more exposure to the language at school, have different experiences using the language with their siblings and same-age peers, and 
acquire the language and use it in an environment that is different from that of heritage speakers (Otheguy, 2013). More precisely, heritage speakers have a home language that is different from the majority language in society (Pascual y Cabo \& Rothman, 2012), whereas this is not the case among monolingual speakers of Spanish. Moreover, heritage speakers may receive input in varieties of Spanish that are influenced by Spanish-English linguistic contact or that have suffered attrition in previous generations, whereas monolingual speakers do not receive this type of input (Pascual y Cabo \& Rothman, 2012). Given the differences between heritage speakers and monolingual speakers, comparing the varieties of Spanish spoken by the two groups can be problematic, especially when studies (such as Polinsky, 2011) consider a monolingual group to be a baseline of comparison (Otheguy, 2013). These comparisons lead studies to concluding that heritage speakers lack some of the linguistic features present in monolingual speech, which promotes the idea that heritage speakers' acquisition of the language is "incomplete", rather than viewing it as simply different from monolingual speakers' (Otheguy, 2013; Pascual y Cabo \& Rothman, 2012). For that reason, Putnam and Sánchez (2013) highlight the need to focus on heritage speakers' grammar acquisition process and maintenance rather than focusing on its "incompleteness" at the end of the acquisition process.

Apart from differing from L2 learners and monolingual speakers in some aspects, heritage speakers also conform a heterogeneous group where individuals differ from each other across "historical, linguistic, educational, affective, and cultural dimensions" (Beaudrie et al., 2014, p. 35). Firstly, it is crucial to know the historic dimension of heritage speakers and their families in order to understand their proficiency in the language. According to Beaudrie et al. (2014), many immigrant families that arrive at the U.S. undergo a quick process of language shift from their main language to English, and this language shift is often times completed within three generations. ${ }^{1}$ With regards to the linguistic dimension, it is important to take into account when and in what order heritage speakers acquired the languages (Beaudrie et al., 2014) and to consider the amount of input that they receive from their families (Benmamoun et al., 2013). Also, it is important to consider whether the

\footnotetext{
${ }^{1}$ It should be noted here that this is a generalization, and that this is not always the case for all heritage speakers.
} 
variety of the heritage language that the speaker uses is prestigious or whether it is stigmatized, because this will have an impact on their choice of using it or not (Beaudrie et al., 2014). Besides linguistic attitudes, it is also essential to take into account to what extent and in which domains heritage speakers use the heritage language (Beaudrie et al., 2014, p. 40). Heritage speakers who are able to use the heritage language at an educational institution will be more likely to develop a more formal register of the language, whereas speakers who only use their heritage language in informal contexts or private spheres will develop a more informal register of the language (Beaudrie et al., 2014). As for the affective dimension, Beaudrie et al. (2014) explain that heritage speakers have different motivations, attitudes, and confidence levels when speaking their heritage language, and this may encourage or discourage them from using it.

\subsection{Measuring Heritage Speakers' Degree of Bilingualism}

In order to understand informants' attitudes toward Spanish and English, and to have a more clear idea of their language history, use, and proficiency, this study uses the Bilingual Language Profile (BLP) Questionnaire (Birdsong et al., 2012; Gertken et al., 2014). The BLP Questionnaire contains 19 multiplechoice questions that are answered using scalar responses and can be completed in less than 10 minutes (Gertken et al., 2014). Moreover, it uses informants' answers to provide a numeric score that goes from -218 to +218 for each informant and each language is placed at the end of the continuum. This study places English at the extreme of -218 and Spanish at the extreme of 218. Informants are placed along a bilingual continuum that allows us to measure heritage speakers' degree of bilingualism in a quantitative manner.

It is important to note here that the BLP Questionnaire is based on informants' self-assessments and does not use tests that are considered to be more objective when measuring informants' proficiency. Even though self-reported evaluations can be viewed as problematic (Treffers-Daller, 2016), previous studies show that bilingual speakers are able to assess their linguistic skills and experiences in ways that reflect their performance in their languages (Gertken et al., 2014). For this reason, this study uses the BLP Questionnaire as a manner to retrieve informants' linguistic information and to measure their linguistic dominance in a standardized manner. Using the BLP 
Questionnaire allows the present study to be comparable to other studies on heritage languages and contributes to its replicability.

Zyzik (2016) mentioned that it is possible to measure the degree of bilingualism of heritage speakers using the BLP Questionnaire. Amengual (2016) used it in his study on the tap and trill contrast in Spanish among 40 heritage speakers and 20 L2 speakers of Spanish in Northern California. The BLP scores allowed Amengual (2016) to classify informants into 3 groups: (a) Spanish-dominant heritage speakers, (b) English-dominant heritage speakers, and (c) L2 speakers of Spanish who were strongly dominant in English. Informants completed a read-aloud task that contained words with phonemic taps and trills in word medial intervocalic position. The data were analyzed acoustically using Praat. First of all, the results for phonemic trills showed that the group of Spanish-dominant heritage speakers produced mostly canonical trills with two or three occlusions, whereas Englishdominant heritage speakers and the group of L2 learners produced most of their trills with no occlusions or with only one occlusion. As for taps, the results showed that the two groups of heritage speakers used more true taps (taps that had one occlusion) than approximant taps or perceptual taps. However, L2 learners used more approximant taps than other types of taps. As for the phonological contrast between taps and trills, all groups used duration to keep this contrast whereas only the group of Spanish-dominant heritage speakers used a combination of duration and the number of occlusions. Amengual (2016) concluded that heritage speakers are a heterogeneous group and that their language dominance, which is measured by the BLP Questionnaire, influences their production of rhotics.

Kim (2018) also used the BLP in her study on focus marking. Kim (2018) analyzed the production data of 24 heritage speakers of Spanish at a Midwestern university, 20 native speakers of English who were learning Spanish as their L2 at a Midwestern university, and 24 monolingual speakers of Spanish from Mexico. Kim (2018) used the BLP scores to show that informants had different degrees of linguistic dominance. More specifically, heritage speakers' BLP scores for English were lower than the BLP scores for L2 learners of Spanish. The BLP scores for Spanish, on the other hand, were lower among L2 learners of Spanish than among heritage speakers. Informants needed to answer prompt questions that elicited their production of sentences and the results showed that informants used a variety of 
strategies to express focus. More precisely, the results for heritage speakers showed that they used post-focal deaccenting in a similar way to L2 learners and used cleft constructions similarly to monolingual speakers.

As in Amengual (2016) and Kim (2018), this study uses the BLP Questionnaire as a tool to retrieve information about heritage speakers' language history, use, proficiency, and attitudes. Like Amengual (2016), the present study compares the production of heritage speakers with different degrees of language dominance in Spanish and English. However, unlike Amengual (2016) and Kim (2018), this study does not compare heritage speakers' production to that of $\mathrm{L} 2$ learners or monolingual speakers. As explained in section 2, this comparison is avoided because heritage speakers differ from monolingual speakers and L2 learners of Spanish in several aspects. Moreover, the present study differs from previous ones because it combines a quantitative and a qualitative analysis to analyze heritage speakers' pronunciation. According to Riazi and Candlin (2014) using a mixed-method approach can help us obtain a more complete view of the topic being analyzed (p. 144). In the present study the quantitative and qualitative analyses are used to obtain a more thorough understanding of heritage speakers' production of /p, t, k/ in Spanish and English.

\section{Stops ANd Voice Onset Time}

Stops are produced when articulators come in contact with each other and airflow is completely blocked for a short period of time (Hualde, 2014, p. 45). An acoustic cue that is often times used to distinguish stops in Spanish and English is Voice Onset Time or VOT. The VOT is the time between the release of a stop closure and the beginning of voicing of the following sound, and is measured in milliseconds (ms; Lisker \& Abramson, 1964, p. 389; Ladefoged \& Johnson, 2014, p. 126). There are different types of VOT depending on when the voicing of the vocal cords starts in relation to the closure of a stop (Lisker \& Abramson, 1964, p. 390; Hualde, 2014, p. 131). On the one hand, the VOT of voiceless stops $(/ \mathrm{p}, \mathrm{t}, \mathrm{k} /)$ in Spanish is short because the vocal cords start vibrating shortly after the stop closure. For that reason, /p, t, k/ in Spanish are described as having a short lag (Zampini, 1998, p. 85). Amengual (2012) claims that the VOT for $/ \mathrm{p}, \mathrm{t}, \mathrm{k} /$ in Spanish is between $0 \mathrm{~ms}$ and $20 \mathrm{~ms}$ (p. 517), Castañeda Vicente (1986) reports that the VOTs of /p, t, k/ in Spanish 
are $6.5 \mathrm{~ms}, 10.4 \mathrm{~ms}$, and $25.7 \mathrm{~ms}$, respectively (p. 98), and Roldán and SotoBarba (1997) report these values to be $13.2 \mathrm{~ms}, 16.4 \mathrm{~ms}$, and $30 \mathrm{~ms}$, respectively. As for /b, d, g/ in Spanish, the vocal cords start vibrating before the stop closure and for that reason they are described as having "voicing lead" and a negative VOT (Zampini, 1998, p. 85; Lisker \& Abramson, 1964, p. 389). On the other hand, the VOT of /p, t, $\mathrm{k}$ / in English varies depending on the linguistic context. More specifically, /p, t, k/ in English are realized with a longer VOT in word-initial position or in the onset of stressed syllables (Hualde, 2014, p.142). In those contexts, /p, t, k/ in English are described as being long-lag voiceless stops (Zampini, 1998, p. 85). Ladefoged and Johnson (2014) use the term "aspirated stops" (2014, p. 125) to refer to voiceless stops in English [p $\mathrm{p}^{\mathrm{h}}$, $\mathrm{t}^{\mathrm{h}}, \mathrm{k}^{\mathrm{h}}$ that have a longer VOT. Lisker and Abramson (1964) report that the VOTs for $\left[\mathrm{p}^{\mathrm{h}}, \mathrm{t}^{\mathrm{h}}, \mathrm{k}^{\mathrm{h}}\right]$ are $58 \mathrm{~ms}, 70 \mathrm{~ms}$, and $80 \mathrm{~ms}$, respectively, and Amengual (2012, p. 517) reports that these values fall between $30 \mathrm{~ms}$ and $120 \mathrm{~ms}$. Nevertheless, aspirated stops in English do not occur in post-tonic positions or in tautosyllabic consonant clusters in which the first consonant is /s/ (Hualde, 2014, p. 142). With regards to /b, d, g/ in English, they tend to be pronounced as unaspirated voiceless stops word initially and they are described as having a short lag (Zampini, 1998, p. 85; Hualde 2014).

The present study focuses on the production of /p, t, k/ in Spanish and English, and only considers VOTs that are positive. This analysis is of interest given the differences between short-lag and long-lag stops mentioned above. In the context of second language acquisition, Flege's Speech Learning Model (SLM; Flege, 1995) hypothesizes the challenges that learners face when acquiring L2 sounds and those hypotheses can be tested when analyzing the VOT of Spanish and English stops. More precisely, according to Flege's SLM (1995), learners may not be able to produce accurate L2 sounds if they are not able to perceive the "targets" with precision (Flege, 1995, p. 238). This could occur because learners are unable to perceive the difference between two L2 sounds or between an L2 sound and a sound in their first language (L1) (Flege, 1995, p. 238). Consequently, learners may group those sounds in a single category and they may be unable to produce the contrast between them (Flege, 1995, p. 238). Based on the first hypothesis of the SLM, if a learner whose L1 is English pronounces the Spanish /p, $\mathrm{t}, \mathrm{k} /$ with a long-lag, they are doing so because they are unable to perceive a contrast between short- and long-lag voiceless stops in Spanish and English (Zampini, 2014:115). 
The present study focuses on the production of $/ \mathrm{p}, \mathrm{t}, \mathrm{k} /$ by heritage speakers who have different degrees of language dominance and it analyzes whether they are using more "Spanish-like" or "English-like" stops (Amengual, 2012, p. 519). Moreover, cognates and non-cognates were included in the stimuli (as in Flege et al., 1998; Amengual, 2012), which allows to determine whether speakers maintain the categories of short-lag and long-lag voiceless stops separate or if they show overlap between them. According to Amengual (2012), this can help us explore whether the two linguistic systems of bilinguals are activated when they are speaking a language or not (p. 526).

The present study also analyzes the effects of the place of articulation of the stop, as previous studies suggest that it has an effect on the VOT (Cho \& Ladefoged, 1999). More precisely, voiceless stops that are pronounced at the back of the oral cavity in Spanish and English have a longer VOT than those that are pronounced at the front of the oral cavity (Lisker \& Abramson, 1964, p. 407). The aforementioned results reported by previous studies in Spanish indicate that the VOT of $/ \mathrm{p} /$ is the shortest one of the three voiceless stops, the VOT of $/ \mathrm{k} /$ is the longest one, and the VOT of $/ \mathrm{t} /$ is between the other two stops. Likewise, the results reported by previous studies in English reflect that $\left[\mathrm{p}^{\mathrm{h}}\right]$ has the shortest VOT, $\left[\mathrm{k}^{\mathrm{h}}\right]$ has the longest VOT, and $\left.\mathrm{t}^{\mathrm{h}}\right]$ has a VOT that is between that of $\left[\mathrm{p}^{\mathrm{h}}\right]$ and $\left[\mathrm{k}^{\mathrm{h}}\right]$.

\subsection{Previous studies on the Voice Onset Time}

Perara-Lunde et al. (2016) analyzed the VOT of English voiceless stops /p, t, $\mathrm{k} /$ among 8 heritage speakers of Spanish at the Heritage Language Program at the University of New Mexico in Albuquerque. Informants had had different levels of exposure to Spanish and English at home during their childhood: two of the informants grew up speaking Spanish at home, one of them grew up speaking English, and the other five informants grew up speaking mostly English, although they also spoke some Spanish. Informants completed an interview and the data were analyzed acoustically using Praat. The overall results showed that the three stops /p, t, k/ had very similar VOTs. The results also showed that informants who grew up speaking English and some Spanish at home had the longest VOT, whereas informants who spoke only Spanish or only English at home during childhood had shorter VOTs. However, informants' speech rate was not measured and it is unclear whether 
the VOT differences were due to differences in participants' speech rates or if they were pronouncing their voiceless stops differently.

Kim (2011) analyzed the production and perception of stops by heritage speakers of Spanish at a Midwestern university in the U.S. The study only included participants who were dominant in English, which was determined by considering their age of acquisition, frequency of use, and language proficiency in the L2. The results for the production of stops showed that heritage speakers pronounced / $\mathrm{p}, \mathrm{t}, \mathrm{k} /$ as unaspirated in Spanish, with a mean VOT of $18.19 \mathrm{~ms}$, whereas they pronounced them as aspirated in English, with a mean VOT of $87.99 \mathrm{~ms}$. Kim (2011) concluded that heritage speakers did not merge their voiceless stops in Spanish and English.

Llama and López-Morelos (2020) also analyzed the production of voiceless stops among heritage speakers of Spanish, although their informants differed from those in Perara-Lunde et al. (2016) and Kim (2011). More specifically, they analyzed the pronunciation of 5 trilingual children aged 6 to 9 years old and 7 trilingual pre-adolescents aged 9 to 16 years old who had Spanish as their heritage language, Canadian English as their dominant language, and Canadian French as their third language. Llama and López-Morelos also retrieved data from monolingual speakers of Spanish, bilingual speakers of English and French, and native speakers of Canadian French and used them as control groups. The results for the VOT of heritage speakers showed that they had created two separate categories for Spanish and English, their two dominant languages, whereas the French VOT was similar to that of English. When looking at their production of Spanish voiceless stops in more detail, Llama and López-Morelos (2020) found that they pronounced them as short lag most of the time, although 10\% of the tokens were produced with a long VOT that was between 42 and $81 \mathrm{~ms}$.

Flege et al. (1998) and Amengual (2012) focused on the production of the voiceless stop / $t /$ and analyzed the effects of cognate words and non-cognate words on its VOT. Flege et al. (1998) analyzed the VOT of English /t/ among 20 monolingual speakers of American English and 41 bilingual speakers who had Spanish as their L1 and English as their L2. The group of bilingual speakers was divided into two different groups: speakers who arrived to the U.S. before they were 21 years old ("Earlier Exposure group") and speakers who arrived to the U.S. after the age of 21 ("Later Exposure group") (p. 161). Their results showed that monolingual speakers of English had longer VOTs than those of bilingual speakers. The differences between the Earlier Exposure group and the Later Exposure group were not statistically significant. With 
regards to the effects of cognate words, Flege et al. (1998) found that there were no statistically significant differences in bilingual speakers' VOT for cognates and non-cognates.

Amengual (2012) analyzed the production of the Spanish / $t$ / among five groups of speakers aged 18 to 32 years old: 10 heritage speakers of Spanish living in Texas, 9 heritage speakers of British English living in Majorca, 10 bilingual speakers from Majorca who had English as their L2, 10 bilingual speakers living in Texas who had Spanish as their L2, and a control group of ten Spanish-Catalan bilingual speakers from Majorca who did not have much experience with English and who were not proficient in the language. Amengual (2012) analyzed the effects of cognate words and non-cognate words in the VOT of /t/. According to Amengual (2012), the use of cognate words is of interest because they are lexical items that overlap in Spanish and English in terms of phonology, semantics, and orthography, and he claims that this "may have an effect on the ability to maintain native-like phonological contrasts across languages" (p. 518). Overall, the results showed that informants from all groups pronounced cognate words with a longer VOT than non-cognate words, although this difference was much smaller for the control group who did not have much experience with English. Moreover, the difference in the pronunciation of cognate words and non-cognate words was statistically significant for at least some speakers in all groups except for the control group. However, when having a closer look at the results of heritage speakers' groups, Amengual (2012) reported that all the heritage speakers of Spanish in the study produced cognates and non-cognates differently, whereas only four of the nine heritage speakers of British English produced them differently (p. 523). Amengual (2012) concluded that bilingual speakers' production of $/ \mathrm{t} /$ is influenced by cross-linguistic phonetic interference and that this interference increases when pronouncing cognate words (p. 528). The current study builds upon Amengual's analysis (2012) and it explores the effects of cognates and non-cognates in the production of the three voiceless stops (/p, $\mathrm{t}, \mathrm{k} /$ ) in Spanish and in English. The research questions are the following:

- What is heritage speakers' VOT of /p, $\mathrm{t}, \mathrm{k} /$ in Spanish and in English like?

- Does heritage speakers' VOT of /p, t, k/ differ depending on their degree of dominance in Spanish or English?

- Does heritage speakers' VOT of /p, t, k/ differ in cognate words and noncognate words? 


\section{Methodology}

\subsection{Informants}

Eight informants completed the tasks in this study. All of them are between 18 and 32 years old and study at a large Midwestern university in the United States. Two of the informants are undergraduate students and the other six are completing their graduate studies. As in Amengual (2019), the present study retrieved information about the order in which informants acquired Spanish and English. If informants acquired both languages from birth their acquisition was considered to be "simultaneous" whereas if they acquired one of the languages before the other early in life their acquisition was "sequential" (p. 956). Based on this classification, informants F5 and F1 are simultaneous heritage speakers, as they acquired Spanish and English at the same time during childhood. The rest of informants are sequential heritage speakers, as they acquired Spanish before English during their childhood. Seven informants obtained negative BLP scores, whereas one informant (F6) obtained a positive BLP score, which indicates that she is more strongly dominant in Spanish than in English. Table 1 presents informants' IDs, age, gender, education, and BLP score. All the participants reported that they have lived their entire lives or most of their lives in an English-speaking country and that they have spent many years in a family where Spanish is spoken. Speakers F4, F1, M1, F6 reported that they had not spent any years in a Spanish speaking country, whereas speakers F2, F5, F3, and M2 had spent between 1 and 5 years in a Spanish speaking country. Moreover, all participants reported that they started to feel comfortable speaking Spanish before or at the same time as they started to feel comfortable speaking English. However, all of them reported that they had taken classes (such as history, math, etc.) in English most of their lives, and none of them had taken classes in Spanish for more than 4 years. With regards to their use of the languages, informants reported that they used mainly English with their friends, and all informants except F6 and F1 reported that they used English more frequently than Spanish in college or at work. Finally, five informants reported that they used Spanish more frequently than English with their families, whereas three of them (F1, F2, F5) reported to use English more frequently than Spanish. 
Table 1. ID, Age, Gender, Acquisition of Languages, and BLP Scores of the Informants in the Present Study

\begin{tabular}{lllll}
\hline ID & Age & Gender & Acquisition of languages & BLP score \\
\hline F4 & 24 & Female & Sequential & -62.206 \\
\hline F5 & 22 & Female & Simultaneous & -59.212 \\
\hline F2 & 26 & Female & Sequential & -54.04 \\
\hline F1 & 26 & Female & Simultaneous & -47.678 \\
\hline F3 & 18 & Female & Sequential & -30.876 \\
\hline M1 & 22 & Male & Sequential & -23.608 \\
\hline M2 & 32 & Male & Sequential & -20.712 \\
\hline F6 & 21 & Female & Sequential & 28.172 \\
\hline
\end{tabular}

Table 2. Mean BLP Values and Standard Deviations for Informants' Language History, Use, Proficiency and Attitudes

\begin{tabular}{llllllllll}
\hline & \multicolumn{2}{c}{$\begin{array}{c}\text { Language } \\
\text { History }\end{array}$} & \multicolumn{2}{c}{$\begin{array}{c}\text { Language } \\
\text { Use }\end{array}$} & \multicolumn{2}{c}{$\begin{array}{c}\text { Language } \\
\text { Proficiency }\end{array}$} & \multicolumn{2}{c}{$\begin{array}{c}\text { Language } \\
\text { Attitudes }\end{array}$} \\
\cline { 2 - 11 } & SP. & EN. & SP. & EN. & SP. & EN. & SP. & EN. \\
\hline Mean & 28.99925 & 41.92675 & 18.53 & 35.97 & 36.60375 & 49.3725 & 49.65625 & 40.2925 \\
\hline STD. & 1.5240 & 7.4736 & 8.3623 & 8.3623 & 8.2685 & 4.6600 & 3.9200 & 11.1041 \\
\hline
\end{tabular}

Informants' responses in the BLP showed that overall, they had a higher score for their language history, use, and proficiency in English than in Spanish, as can be seen in Table 2. As for linguistic attitudes the overall results showed that they had a higher score for Spanish than for English. However, when analyzing the results in more detail, there was one informant (informant F4, who was more strongly dominant in English), who had a slightly higher score for her language attitudes in English than in Spanish.

\subsection{Materials and Recordings}

Informants completed the BLP Questionnaire, a read-aloud task in Spanish and in English, and a follow-up interview. In the read-aloud task in Spanish informants needed to read 18 carrier sentences that contained the word of interest and they had to read each sentence three times. All the sentences were presented in three blocks. The sentences were randomly presented in the first block and that same order was repeated in the second and the third blocks. 
There were 18 words of interest in Spanish with the voiceless stops /p, t, k/ word initially and in stressed positions followed by the grapheme $<a>$. This grapheme represented the vowel /a/ in Spanish. 9 of those words were cognates chosen by the researcher in Spanish and in English, whereas the other 9 words were not cognates. Table 3 shows the words of interest in Spanish. The researcher explained the instructions of the task in Spanish first and informants completed the task in Spanish. After that, the researcher switched to English and explained the instructions of the task in English to make sure that the informant had activated the appropriate "language mode" for the task (Grosjean, 2001, 122). In the read-aloud task in English informants needed to read 18 carrier sentences that contained the word of interest and they had to read each sentence three times. As in the task in Spanish, all the sentences in English were presented in three blocks. The sentences were randomly presented in the first block and that same order was repeated in the second and third blocks. There were 18 words of interest in English with the voiceless stops / $\mathrm{p}, \mathrm{t}, \mathrm{k} /$ word initially and in stressed positions followed by the grapheme $<a>$. It should be noted here that the grapheme $<a>$ represented the vowels $/ æ /$ and $/ \mathbf{a} /$ in the task in English, which are different from the Spanish vowel /a/. However, the grapheme $<\mathrm{a}>$ was included in both tasks to control for the context of $/ \mathrm{p}, \mathrm{t}, \mathrm{k} / \mathrm{as}$ much as possible and to make sure that they were pronounced before non-high vowels. The context was controlled as much as possible because previous studies found an effect of the following vowel on the VOT of /p, t, k/ (Yavaş \& Windermuth, 2006, p. 253). More precisely, /p, t, $\mathrm{k} /$ have longer VOTs in English when they are followed by high vowels than by non-high vowels (Yavas \& Windermuth, 2006, p. 260). For the task in English there were also 9 words that were cognates in English and in Spanish, whereas the other 9 words were not cognates. Table 4 shows the words of interest in English.

Table 3. Words of Interest in Spanish

\begin{tabular}{llllll}
\hline & $/ \mathrm{p} /$ & & /t/ & & $/ \mathrm{k} /$ \\
\hline Cognates & Non-Cognates & Cognates & Non-Cognates & Cognates & Non-Cognates \\
\hline Parque & Parco & Tarde & Tanto & Carro & Cacho \\
Palma & Palta & Tarta & Tanda & Calma & Cama \\
Pacto & Palpo & Tacto & Talque & Cactus & Caldo \\
\hline
\end{tabular}


Table 4. Words of Interest in English

\begin{tabular}{llllll}
\hline & $/ \mathrm{p} /$ & & & & $/ \mathrm{k} /$ \\
\hline Cognates & Non-Cognates & Cognates & Non-Cognates & Cognates & Non-Cognates \\
\hline Park & Path & Tardy & Tamper & Car & Cast \\
Palm & Parse & Tart & Tarp & Calm & Carve \\
Pact & Pal & Tact & Tap & Cactus & Cabby \\
\hline
\end{tabular}

The words of interest were inserted in the middle of carrier sentences and (1) and (2) are examples of the types of sentences that informants needed to read.

(1) Dices parque para mí.

(2) She says park to me.

The read-aloud tasks also contained 5 distractor words in Spanish and 5 distractor words in English without /p, t, k/ to make sure that participants were not focusing in the sounds of interest when completing the task. The distractor words aimed to elicit the production of a variety of sounds (such as rhotics) and they were inserted in the middle of carrier sentences, as can be seen in (3) and (4). Even though the carrier sentences for distractors contained $/ \mathrm{p}, \mathrm{t} /$, it is unlikely that informants focused on these sounds, given that these carrier sentences were repeated during the whole task.

(1) Repites garra para mí.

(2) She says rare to me.

Informants were told to read the sentences at a natural pace (as if they were talking to another person, not too slow and not too fast, as in Amengual, 2012) and they read each sentence from a PowerPoint slide on a computer screen. Moreover, the PowerPoint slides had automatic transitions so that informants could see each sentence for 4 seconds. The objective of having transition times was to minimize the effects of their reading pace on the VOT and to control differences in speech rate. The transitions were set at 4 seconds after piloting the study with five bilingual speakers of Spanish and English. Three of those 
speakers were native speakers of Spanish who learned English as an L2, whereas the other two were native speakers of English who learned Spanish as an L2.

After the reading tasks in Spanish and in English, informants needed to answer questions from a follow-up interview (available in appendix A) in the language they chose, which could be Spanish, English, or both. The interview was created in order to know more about informants' background, their attitudes towards the two languages and their pronunciation, and to add more information to the answers that informants gave in the BLP Questionnaire. Additionally, the follow-up interview allowed for exploring informants' attitudes towards codeswitching and Spanglish. Their answers to these questions provided a deeper understanding of their opinions about combining the two languages and it gave the opportunity to explore whether they had been exposed to more prescriptive or descriptive views on this topic.

The reading tasks and the interview were recorded using a Blue SnowBall microphone connected to a laptop through the USB and the software Audacity (Version 2.1.2) at a sampling rate of $44100 \mathrm{~Hz}$. The PowerPoint slides were presented using a separate computer screen that was placed behind the microphone at informants' eye level. The computer screen and microphone were always placed at approximately the same distance from the informant. All the recordings were made at the same quiet university office.

\subsection{Data Analysis}

The VOT of /p, t, k/ was segmented manually using Praat (Boersma \& Weenink, 2017). The onset of the VOT was segmented immediately before the release burst of the stop whereas the offset of the VOT was segmented at the beginning of the following vowel. More specifically, the offset was segmented immediately before the first voicing cycle that was regularly repeated in the waveform (as in Amengual, 2012, p. 522). The same procedure was followed in Spanish and English, as can be seen in Figs. 1 and 2. When stops had more than one release burst, the onset of VOT was segmented immediately before the first release burst. After segmenting VOTs, a script extracted the values automatically for the 849 tokens that were analyzed. 


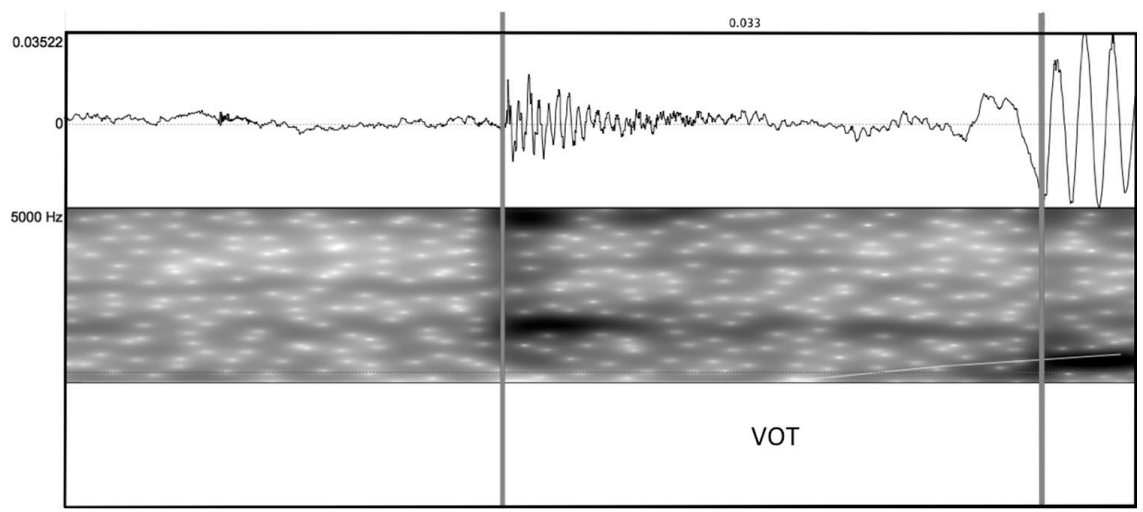

Figure 1. Segmentation of the VOT (33 ms) of the word initial / k/ in the word cactus in Spanish.

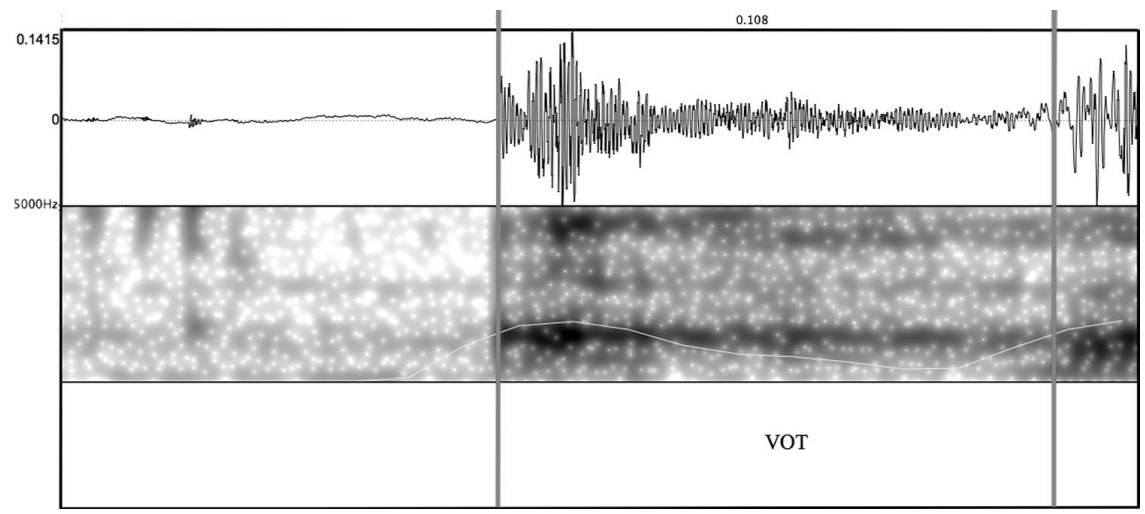

Figure 2. Segmentation of the VOT $(108 \mathrm{~ms})$ of the word initial $/ \mathrm{k} /$ in the word carve in English.

This study analyzes the effects of the following independent variables on the VOT, the dependent variable:

1. Place of articulation

$$
\begin{aligned}
& / \mathrm{p} / \text { parque } \\
& / \mathrm{t} / \text { tanto } \\
& / \mathrm{k} / \text { carro }
\end{aligned}
$$


2. Language

Spanish

English

3. Status of the word as a cognate or non-cognate in Spanish and English

Cognate pacto

Non-cognate cama

4. Informants' language dominance as measured by the BLP score.

F6

M2

M1

F3

F1

F2

F5

F4
28.152

$-20.712$

$-23.608$

$-30.876$

$-47.678$

$-54.04$

$-59.212$

$-62.206$

\subsection{Statistical Analysis}

The statistical analyses in this study were carried out using the R Project for Statistical Computing (Version 3.3.2) using the packages languageR, lme4, lmerTest, and party. First, mixed-effects linear regression modeling was carried out to analyze the effects of place of articulation (/p, t, k/), language (Spanish/ English), status of the word as a cognate or non-cognate (cognate/ non-cognate), informants' language dominance, and the interactions between the variables. When performing the mixed-effects linear regression modeling, the independent variables were added stepwise, and word was included as a random factor. The statistical significance level is set at $\mathrm{p}<0.05$.

\section{ResULtS}

\subsection{Results for the Voice Onset Time}

The best fit model for the VOT includes language, place of articulation, language dominance, cognate, the interaction between language and language dominance, and the interaction between cognate and language. Table 5 presents the results of the best fit model. ${ }^{2}$

\footnotetext{
${ }^{2}$ The significance code is the following: $0^{(* * *)}, 0.001^{(* *)}, 0.01^{(*)}, 0.05^{\prime},, 1$.
} 


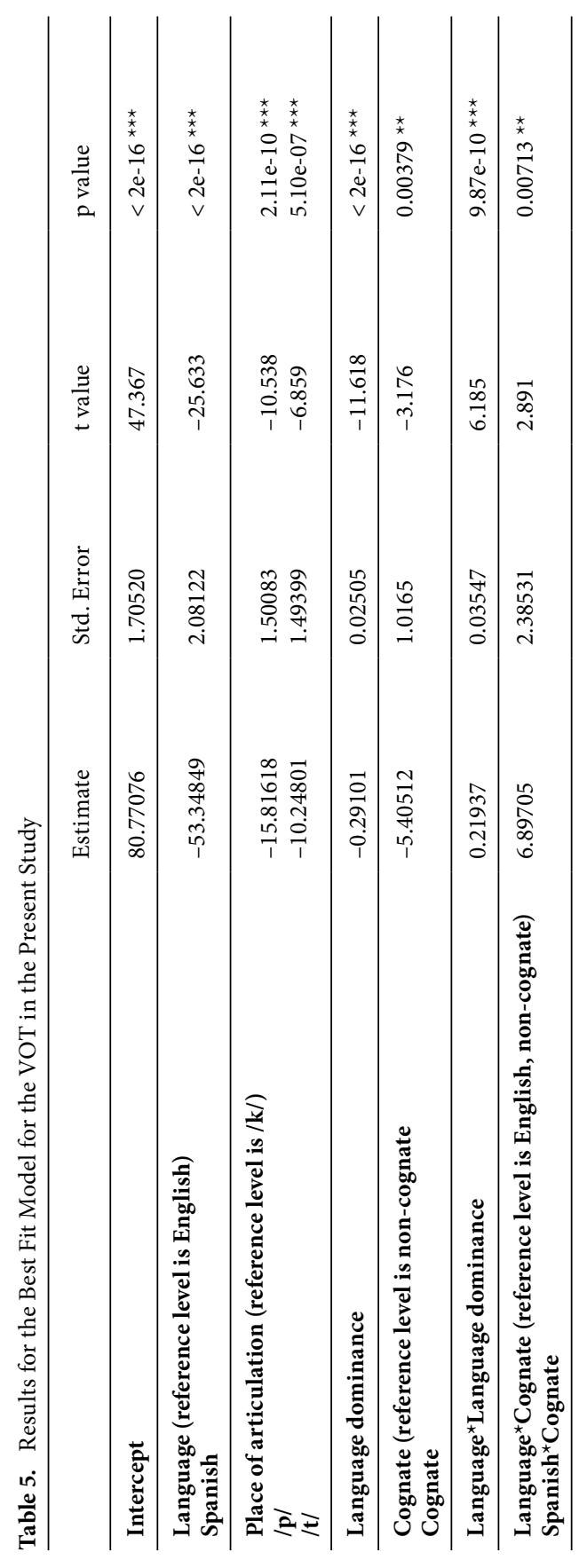


Table 6. Overall Results of the VOT in Spanish and in English

\begin{tabular}{ll}
\hline & VOT (ms.) \\
\hline Spanish & 21.518 \\
\hline English & 79.415 \\
\hline
\end{tabular}

The overall results show that the VOT is shorter for Spanish than for English, as can be seen in Table 6, and the difference is statistically significant $(p<2 \mathrm{e}-16)$. The results also show that the place of articulation of the stop has an effect on VOT. More precisely, /p/ has the shortest VOT in the present study and $/ \mathrm{k} /$ has the longest VOT. The VOT of $/ \mathrm{t} /$ is in between that of $/ \mathrm{p} /$ and $/ \mathrm{k} /$, as can be seen in Table 7 . The difference between $/ \mathrm{p} /$ and $/ \mathrm{k} /$ is statistically significant $(p=2.11 \mathrm{e}-10)$ and the difference between $/ \mathrm{t} /$ and $/ \mathrm{k} /$ is also statistically significant. When re-leveling the intercept, the difference between $/ \mathrm{p} /$ and $/ \mathrm{t} /$ is also statistically significant $(p=0.000903)$.

Table 7. Overall Results of the VOT of $/ \mathrm{p}, \mathrm{t}, \mathrm{k} /$

\begin{tabular}{lll}
\hline & VOT $(\mathrm{ms})$. & Standard Deviation: \\
\hline$/ \mathrm{p} /$ & 42.862 & 33.845 \\
\hline$/ \mathrm{t} /$ & 49.087 & 33.152 \\
\hline$/ \mathrm{k} /$ & 59.869 & 31.709 \\
\hline
\end{tabular}

The effect of the BLP on VOT is statistically significant. More specifically, informants who have a lower BLP score have a longer VOT value for $/ \mathrm{p}, \mathrm{t}, \mathrm{k} /$ and this difference is statistically significant $(p<2 \mathrm{e}-16)$. Moreover, the results show that the overall effect of cognates and non-cognates on VOT is statistically significant $(p=0.00379)$. More precisely, the overall VOTs are longer for non-cognates than for cognates.

With regards to the interaction between language and language dominance, the results show that informants who have lower BLP scores pronounce / $\mathrm{p}, \mathrm{t}, \mathrm{k} /$ in English with a longer VOT. However, informants who have higher BLP scores pronounce / $\mathrm{p}, \mathrm{t}, \mathrm{k} /$ in English with a shorter VOT, as can be seen in Figure 3. As for Spanish, the informant who has the lowest BLP score has the longest VOT for / $\mathrm{p}, \mathrm{t}, \mathrm{k} /$ in Spanish and the informant who has the highest BLP score has the shortest VOT for $/ \mathrm{p}, \mathrm{t}, \mathrm{k} /$ in Spanish. However, the overall VOT for / $\mathrm{p}, \mathrm{t}, \mathrm{k} /$ in Spanish does not decrease as the BLP score increases and those results are explained in more detail in Section 5.2. by combining the BLP results together with the follow-up interview that informants completed. 
With regards to the interaction between language and cognate, /p, t, $\mathrm{k} /$ in English are pronounced with a shorter VOT when they are cognates than when they are not. With regards to Spanish, /p, t, k/ are pronounced with a longer VOT in cognates than in non-cognates, as can be seen in Figure 4. However, the difference between cognates and non-cognates is bigger in English than in Spanish.

VOT for /p, t, $\mathrm{k}$ / in English and Spanish in this study

$\triangle$ ENGLISH VOT $\square$ SPANISH VOT

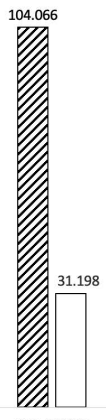

BLP -62.206
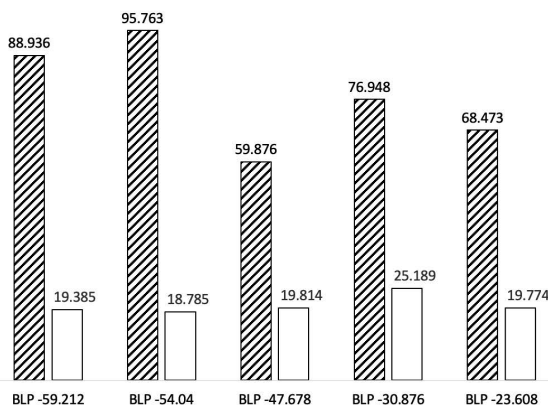

BLP -54.04

BLP -47.678

BLP -23.608
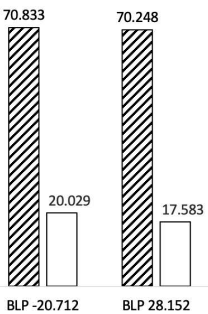

BLP 28.152

Figure 3. Graph with the results for the VOT of /p, t, k/ in English and in Spanish

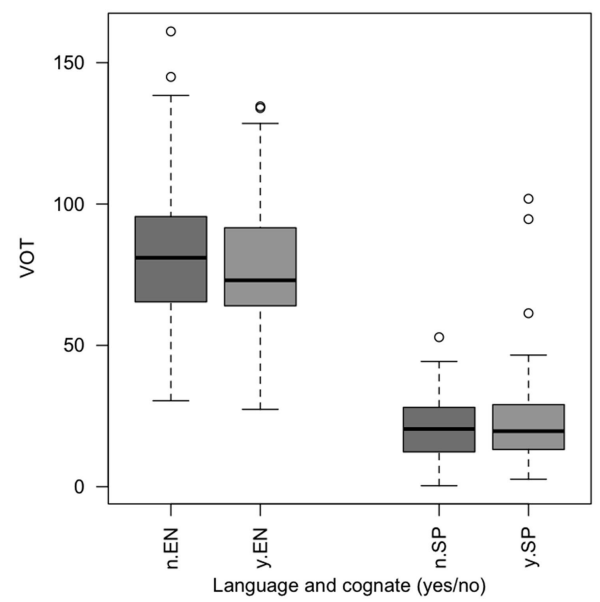

Figure 4. Boxplot with VOTs for cognates (y) and non-cognates (n) in English and in Spanish 


\subsection{The Interview}

Recall that VOTs of /p, $\mathrm{t}, \mathrm{k} /$ in English are shorter as the BLP score increases, as can be seen in Figure 3. This means that VOTs of /p, t, k/ in English are shorter among informants who are more strongly dominant in Spanish than informants who are more strongly dominant in English. More precisely, the three informants who reported to be more strongly dominant in English (with BLP scores of $-62.206,-59.212,-54.04$ ) are the ones with the longest VOT, whereas the three informants who reported to be more strongly dominant in Spanish (with BLP scores of $-23.608,-20.712,28.152$ ) have a shorter VOT for /p, t, k/ in English.

The results of the BLP can be combined together with the results of the follow-up interview to understand the variation in VOT. First of all, the three informants who have the highest BLP scores are the only informants who chose to complete the interview in Spanish, whereas the rest of the informants completed it in English. Moreover, when informants were asked if they identified themselves more with English or Spanish or if they identified themselves equally with both languages, those three informants with the highest BLP scores were the only ones who answered that they identify themselves more with Spanish than with English. The rest of the speakers said that they identify themselves equally with both languages or they identify themselves more with English. In (1), the informant with the highest BLP score (BLP score of 28.152) explains that she identifies herself more with Spanish at the moment of the recording, although this was not always the case. More precisely, she explains that she needed to act like a different person when she was at school.

(1) "Well, I feel that I identify more with Spanish because I grew up speaking Spanish ... so my ... uh ... that's all I knew, my culture and everything was only at home, and then at school I had to act like a different person, almost, so I could fit in with everyone else." (Informant F6)

Consequently, the results show that informants who are more strongly dominant in Spanish, who identify themselves more with the Spanish language, and who choose to do the interview in Spanish have a shorter VOTs in English than the rest of the informants. The only exception here is the 
informant F1 (with a BLP score of -47.678), who has the shortest VOTs for /p, $\mathrm{t}, \mathrm{k} / \mathrm{in}$ English in this study despite the fact that she reported to be more strongly dominant in English. However, when looking at the responses from the follow-up interview, F1 claims that she does not want to be identified as a person with "acento americano" or "acento gringa". This is the informant's response when she is asked if it is important to pronounce words in English and Spanish differently or not.

(2) "Pues yo creo que ... que sí es importante tener esa distinción porque eso como lo marca a uno como ... me dicen a mí que tengo un acento americano ... o como acento gringa ... and I’m like ... ¡ Noooo! ¡No lo tengo! ... pero sí porque sé que no tengo la pronunciación perfecta ... entonces yo ... eso me marca a veces." (Informant F1)

With regards to the results for the VOT of /p, t, $\mathrm{k} /$ in Spanish, the informant who is more strongly dominant in English (BLP score of -62.206) has the longest VOT (31.198 ms) whereas the informant who is more strongly dominant in Spanish (BLP score of 28.152) has the shortest VOT (17.583 ms) in this study. However, the results for the other informants do not show that VOTs in Spanish are shorter as the degree of dominance in Spanish increases. More precisely, the mean VOT in Spanish for all informants except that of informants F3 (BLP score of -30.876) and F4 (BLP score of -62.206) is between $17.583 \mathrm{~ms}$ and $20.029 \mathrm{~ms}$, which means that overall most of the speakers pronounce / $\mathrm{p}, \mathrm{t}, \mathrm{k} /$ in Spanish similarly and with a short VOT. The VOT for /p, t, k/ in Spanish is longer for informant F3, who has a mean VOT of 25.189 $\mathrm{ms}$, and for speaker F4, who has a mean of $31.198 \mathrm{~ms}$. A closer look at the BLP results shows that what these two informants have in common is that they report to have a lower proficiency in Spanish than other informants. More specifically, informants F3 and F4's BLP scores for the section on language competence in Spanish is 24.97 (out of 54.48 possible points), whereas the rest of the informants' self-reported competence for that part is between 31.78 and 45.4. Moreover, in the BLP questionnaire informants had to answer the question "How well do you read Spanish?" and both informants self-rated their reading skills in Spanish as 2 out of 6, whereas the rest of the informants self-rated their reading skills between 3 and 6 in Spanish. During the follow-up interview, speaker F4 also comments on her pronunciation in Spanish. 
(3) "Uh ... I think it's harder for me to pronounce certain words in Spanish and certain sounds in Spanish." (Informant F4)

With regards to the effect of cognate words on the VOT, the follow-up interview shows that some of the informants are aware of several similarities and differences that we find among cognates in Spanish and English. For instance, when informants F3 (BLP score of -30.876) and F5 (BLP score of -59.212) are asked about pronunciation in Spanish and English, they say that it is very similar and they give examples of cognate words, which we can see in (4-5).

(4) "For example . . like ... Americans like to use the word $t a . . t a .$. taco, but we say taco, the $<\mathrm{a}>$ is more pronounced and then you pronounce more the, so it just depends on where you come from and how you are raised to say it" (Informant F3).

(5) "I think it is similar...Like car and carro, but in some places they say coche ... or uh ... some words are similar ... they look and are spelled kind of similar and just pronounced differently, café and coffee, they sound similar ... but that just could be because I speak both languages." (Informant F5)

Even though informants mention cognate words with /t, k/ in word initial position, none of them mention that there are differences in the pronunciation of word-initial voiceless stops. Moreover, when informant F3 is asked whether the $<\mathrm{t}>$ in taco in Spanish and English is different or not, she says that they are pronounced the same.

\section{Discussion ANd CONCLUSIONS}

The VOT for $/ \mathrm{p}, \mathrm{t}, \mathrm{k} /$ in the present study is shorter in Spanish (21.518 ms) than in English (79.415 ms), as in Kim (2011) and Llama \& López-Morelos (2020), and these results indicate that overall informants pronounce English stops as aspirated and Spanish stops as unaspirated. Moreover, the results show that the VOT is longer for stops that are articulated at the back of the oral cavity than for stops articulated at the front of the oral cavity. More precisely, the mean VOT of $/ \mathrm{k} /$ is the longest of the three voiceless stops, 
whereas the VOT of /p/ is the shortest one. The VOT of / $t /$ is in between that of $/ \mathrm{p} /$ and $/ \mathrm{k} /$. Given cross-linguistic tendencies, these results are expected (Lisker \& Abramson, 1964). The results for English /p, t, k/ are similar to those in Lisker and Abramson (1964), as the VOT range for English /p, t, k/ in the present study $(73.027-87.000 \mathrm{~ms})$ is similar to the VOT reported by them (58-80 ms). Moreover, the results for Spanish in the present study resemble those in Roldán and Soto-Barba (1997) given that the VOT range for Spanish $/ \mathrm{p}, \mathrm{t}, \mathrm{k} /$ in the present study $(13.547-32.290 \mathrm{~ms})$ is similar to the one reported by them (13.2-30 ms).

With regards to informants' production of /p, $\mathrm{t}, \mathrm{k} /$ in English, the results from the quantitative analysis show that VOTs are shorter as BLP score increases. In other words, VOTs of /p, $\mathrm{t}, \mathrm{k} /$ in English are shorter among informants who are more strongly dominant in Spanish than among informants who are more strongly dominant in English. The results from the follow-up interview support the results from the quantitative analysis as they show that informants who are more strongly dominant in Spanish according to the BLP are also the ones who identify themselves more with Spanish than with English. Moreover, the follow-up interview allows us to know more about informants' linguistic attitudes and gives us the opportunity to hypothesize why informant Fl's VOTs for /p, t, k/ in English are shorter than the other informants', despite the fact that she is more strongly dominant in English. More precisely, informant Fl's reluctance to being identified as a person with an "American accent" could be the reason for having such short VOTs in English. However, the reason why her VOT for $/ \mathrm{p}, \mathrm{t}, \mathrm{k} /$ in Spanish is not shorter than the rest of the informants' remains unanswered.

As for VOT in Spanish, informants F4 and F3 are those with the longest VOTs. Informant F4 has the lowest BLP score (-62.206), which means that she is less dominant in Spanish than the other informants. This is not the case for informant F3, who has a BLP score of -30.876 . However, both of these informants reported to have a lower proficiency in Spanish (24.97 points of 54.48 possible points) than the rest of the informants in the study. Moreover, both of these informants obtained lower self-reported scores for their reading skills in Spanish than the rest of the informants and this could have an effect on their results given that the task required them to read sentences in Spanish out loud. The follow-up interview was able to expand on this, as informant F4 reported to have difficulties pronouncing certain sounds in Spanish when she was interviewed. 
The results also show that $/ \mathrm{p}, \mathrm{t}, \mathrm{k} /$ are pronounced differently in cognates and non-cognates. More specifically, voiceless stops in English are pronounced with a shorter VOT or in a more Spanish-like manner when they are cognates than when they are not. With regards to Spanish, voiceless stops are pronounced with a longer VOT or in a more "English-like manner" in cognates than in non-cognates. The follow-up interview showed that informants are aware of several similarities and differences that are present in cognate words with /p, t, k/ in Spanish and English, but they do not mention these specific sounds word-initially.

A more detailed analysis of cognates in both languages shows that only cognates with $/ \mathrm{p} /$ and $/ \mathrm{k} /$ in English are pronounced with a shorter VOT than non-cognates with $/ \mathrm{p} /$ and $/ \mathrm{k} /$, whereas this is not the case for cognates with $/ \mathrm{t} /$. In Spanish, cognates with $/ \mathrm{p} /$ and $/ \mathrm{k} /$ are pronounced with a longer VOT than non-cognates with $/ \mathrm{p} /$ and $/ \mathrm{k} /$, whereas this does not occur with cognate words with / $t /$. Moreover, the results show that there are certain cognate words that behave differently from others. For instance, as Table 8 shows, the cognate word cactus is pronounced with a longer VOT in Spanish than other cognate words with word-initial / $\mathrm{k} /$, such as calma.

The reason for this could be that some informants may be more familiar with the words nopal or cacto in Spanish than with the word cactus and consequently, they could be slowing down their reading pace when encountering this word. Another option could be that those informants who are not familiar with the term could be pronouncing this word in English. For instance,

Table 8. Mean VOT for $/ \mathrm{p}, \mathrm{t}, \mathrm{k} /$ in Each Cognate Word in English and Spanish

\begin{tabular}{llll}
\hline English & VOT $(\mathrm{ms})$. & Spanish & VOT $(\mathrm{ms})$. \\
\hline pact & 67.969 & pacto & 13.254 \\
\hline palm & 76.984 & palma & 14.574 \\
\hline park & 64.498 & parque & 14.080 \\
\hline tact & 80.130 & tacto & 18.294 \\
\hline tardy & 79.261 & tarde & 19.231 \\
\hline tart & 77.220 & tarta & 19.636 \\
\hline cactus & 75.074 & cactus & 37.817 \\
\hline calm & 82.299 & calma & 31.379 \\
\hline car & 88.283 & carro & 30.665 \\
\hline
\end{tabular}


informant F5 explains in (6) that there are cases in which she uses the English pronunciation of words when speaking Spanish.

(6) "When I don't feel comfortable pronouncing something because I think it's wrong, I would say it in English. The English word or like the English pronunciation of it." (Informant F5)

It should be noted here that the word cactus is the only cognate word in the present study that is spelled exactly alike in both Spanish and English, whereas the rest of the cognate words differ in their spelling. A further study with more cognate words that are spelled exactly alike in both languages would help to clarify this. Moreover, future studies should consider the frequency effects of words that are included in the stimuli.

Overall, this study shows that speakers' sociolinguistic attributes correlate with differences in pronunciation. The main contribution of this study is that it collects data on speakers' language history, use, attitudes, and proficiency by combining the BLP Questionnaire and a follow-up interview, which is an innovative methodology in the study of stop production among heritage speakers. This methodology allows us to collect information not only on informants' language background, but also on their opinions on the production of $/ \mathrm{p}, \mathrm{t}, \mathrm{k} /$ and more generally, on their opinions and intuitions about the pronunciation in Spanish and English. This study also contributes to our knowledge of the use of cognates and non-cognates in Spanish and in English by bilingual speakers. As in Amengual (2012), the current study finds that overall, cognate words in Spanish are pronounced with a longer VOT than non-cognate words. Moreover, the effect of cognate words is also visible in the production of $/ \mathrm{p}, \mathrm{t}, \mathrm{k} /$ in English in the present study. As Amengual (2012) suggests, this could be explained through Flege's SLM (Flege, 1995), as speakers have created separate phonetic categories for their Spanish and English voiceless stops and they "dissimilate" their production of these sounds in non-cognate words more than in cognate words. Moreover, the present study expands on previous analyses by exploring the effects of cognate words on the VOT of the three voiceless stops rather than focusing on one stop. However, when looking at the results for each of the stops separately, the results seem to be similar to Flege et al. (1998) and different from Amengual (2012). More specifically, the present study finds that only cognates beginning with $/ \mathrm{p} /$ and $/ \mathrm{k} /$ in Spanish have a shorter VOT 
than non-cognates and only cognates beginning with $/ \mathrm{p} /$ and $/ \mathrm{k} /$ have a shorter VOT in English. Consequently, the present study highlights the need to check all the voiceless stops when exploring the effect of cognates because there are differences depending on the place of articulation of the voiceless stop.

A further study with more informants would contribute to the generalizability of the data and would allow us to acquire a deeper knowledge of the production of $/ \mathrm{p}, \mathrm{t}, \mathrm{k} /$. Moreover, future studies should consider variables that were not included in the present study, such as the location where informants were born, the age of arrival for informants who were born outside the U.S., the location in the U.S. where participants grew up, the variety of Spanish that heritage speakers are exposed to, and whether they travel to Spanishspeaking countries often or not. Furthermore, an analysis that includes cognate words that are spelled exactly alike in Spanish and English would allow to check whether those cognates behave like cognates that have a different spelling in the two languages or not. Finally, including a more objective measure to evaluate informants' proficiency in the heritage language would give the opportunity to confirm or refute the hypothesis that informants who have a lower proficiency in Spanish have longer VOTs.

\section{REFERENCES}

Amengual, M. (2012). Interlingual influence in bilingual speech: Cognate status effect in a continuum of bilingualism. Bilingualism: Language and Cognition, 15(3), 517-530.

Amengual, M. (2016). Acoustic correlates of the Spanish tap-trill contrast: Heritage and L2 Spanish speakers. Heritage Language Journal, 13(2), 88-112.

Amengual, M. (2019). Type of early bilingualism and its effects on the acoustic realization of allophonic variants: Early sequential and simultaneous bilinguals. International Journal of Bilingualism, 23(5), 954-970.

Benmamoun, E., Montrul, S., \& Polinsky, M. (2013). Defining an “ideal” heritage speaker: Theoretical and methodological challenges. Reply to peer commentaries. Theoretical Linguistics, 39(3-4), 259-294.

Beaudrie, S. M., Ducar, C., \& Potowski, K. (2014). Heritage language teaching: Research and practice. McGraw-Hill Education Create.

Birdsong, D., Gertken, L.M., \& Amengual, M. (2012). Bilingual language profile: An easy-touse instrument to assess bilingualism. COERLL, University of Texas at Austin. Retrieved January 20, 2012, from https://sites.la.utexas.edu/bilingual/ 
Boersma, P., and Weenink, D. (2017). Praat: Doing phonetics by computer [Computer program]. Version 6.0.22. http://www.praat.org/

Brown, E. L., \& HArper, D. (2009). Phonological evidence of interlingual exemplar connections. Studies in Hispanic and Lusophone Linguistics, 2(2), 257-274.

Castañeda Vicente, M. L. (1986). El VOT de las oclusivas sordas y sonoras españolas. Estudios de fonética experimental, 2, 91-110.

Cho, T., \& Ladefoged, P. (1999). Variation and universals in VOT: Evidence from 18 languages. Journal of Phonetics, 27(2), 207-229.

Flege, J. E. (1995). Second-language speech learning: Theory, findings, and problems. In W. Strange (Ed.), Speech Perception \& Linguistic Experience: Issues in Cross-Language Research (pp. 233-277). York Press.

Flege, J. E., Frieda, E. M., Walley, A. C., \& Randazza, L.A. (1998). Lexical factors and segmental accuracy in second language speech production. Studies in Second Language Acquisition, 20(2), 155-187.

Gertken, L. M., Amengual, M., \& Birdsong, D. (2014). Assessing language dominance with the bilingual language profile. In Leclerc q, P, Edmonds, A., \& Hilton, H. (Eds). Measuring L2 proficiency: Perspectives from SLA (pp. 208-225). De Gruyter.

Grosjean, F. (2001). The bilingual's language modes. One mind, two languages: Bilingual language processing. Wiley.

Hualde, J. I. (2014). Los sonidos del español: Spanish language edition. Cambridge University Press.

Kim, J. Y. (2011). Discrepancy between the perception and production of stop consonants by Spanish heritage speakers in the United States [Master's thesis, Korea University].

Kim, J. Y. (2018). Heritage speakers' use of prosodic strategies in focus marking in Spanish. International Journal of Bilingualism, 23(5), 986-1004.

Ladefoged, P., \& Johnson, K. (2014). Airstream mechanisms and phonation types. A Course in Phonetics (7th ed.). Cengage Learning.

Lipski, J. M. (2008). The importance of Spanish in the United States. Varieties of Spanish in the United States. Georgetown University Press.

Lisker, L., \& Abramson, A. S. (1964). A cross-language study of voicing in initial stops: Acoustical measurements. Word 20(3), 384-422.

Llama, R., \& López-Morelos, L.P. (2020). On heritage accents: Insights from Voice Onset Time production by trilingual heritage speakers of Spanish. In E. Babatsouli \& M. J. Ball (Eds.), An anthology of bilingual child phonology (pp. 209-231). Multilingual Matters Limited. 
Lopez, M. H., \& Gonzalez-Barrera, A. (2013, September 5). What is the future of Spanish in the United States? http://www.pewresearch.org/fact-tank/2013/09/05/ what-is-the-future-of-spanish-in-the-united-states/

Lopez, M. H., Krogstad, J. M., \& Flores, A. (2018, April 2). Most Hispanic parents speak Spanish to their children, but this is less the case in later immigrant generations. http:// www.pewresearch.org/fact-tank/2018/04/02/ most-hispanic-parents-speak-spanish-to-their-children-but-this-is-less-the-case-in-laterimmigrant-generations/

Montelongo, J. A., Hernández, A., \& Herter, R. J. (2011). Identifying Spanish-English cognates to scaffold instruction for Latino ELs. The Reading Teacher, 65(2), 161-164.

Otheguy, R. (2013). The linguistic competence of second-generation bilinguals: A critique of “incomplete acquisition." Romance Linguistics, 301-320.

Pascual y Cabo, D., \& Rothman, J. (2012). The (il)logical problem of heritage speaker bilingualism and incomplete acquisition. Applied Linguistics, 33(4), 450-455.

Perara-Lunde, M., Lindsey, J., \& File Muriel, R. J. (2016). Voice onset timing in the English of Spanish heritage speakers. Revista Interacción, 14, 17-26.

Pew Hispanic Center. (2018, April 2). Share of Hispanic parents who speak Spanish to their children declines across immigrant generations. http://www.pewresearch.org/facttank/2018/04/02/most-hispanic-parents-speak-spanish-to-their-children-but-this-is-lessthe-case-in-later-immigrant-generations/ft_18-04-02_spanishlang_parents_generation/

Polinsky, M. (2011). Reanalysis in adult heritage language: A case for attrition. Studies in Second Language Acquisition, 33, 305-328.

Putnam, M. T., \& Sánchez, L. (2013). What's so incomplete about incomplete acquisition? A prolegomenon to modeling heritage language grammars. Linguistic Approaches to Bilingualism, 3(4), 478-508.

Rajiv, R., \& Ronquest, R. (2015). The heritage Spanish phonetic/ phonological system: Looking back and moving forward. Studies in Hispanic and Lusophone Linguistics, 8(2), 403-414.

Rajiv, R. (2019). The phonological system of adult heritage speakers of Spanish in the United States. In S. Colina \& F. Martínez-Gil (Eds.), The Routledge Handbook of Spanish Phonology (439-452). Routledge.

Riazi, A. M., \& Candlin, C. N. (2014). Mixed methods research in language teaching and learning: Opportunitites, issues and challenges. Language Teaching, 47(2), 135-173.

Roldán, Y., \& Soto-Barba, J. (1997). El V.O.T. de /p-t-k/ y /b-d-g/ en el español de Valdivia: Un análisis acústico. Estudios Filológicos, 32, 27-33. 
Treffers-Daller, J. (2016). Language dominance: The construct, its measurement, and operationalization. In C. Silva-Corvalán \& J. Treffers-Daller (Eds.), Language Dominance in Bilinguals: Issues of Measurement and Operationalization (pp. 235-266). Cambridge University Press.

United States Census Bureau. (2017). Quick Facts United States. https://www.census.gov/ quickfacts/fact/table/US/PST045217\#qf-headnote-b

Valdés, G. (2001). Heritage language students: Profiles and possibilities. In T. G. Wiley, J. Kreeft Peyton, D. Christian, S. C. K. Moore, \& Na Liu (Eds.), Handbook of heritage, community, and native American languages in the United States (pp. 37-77). Routledge.

Yavaş, M., \& Wildermuth, R. (2006). The effects of place of articulation and vowel height in the acquisition of English aspirated stops by Spanish speakers. IRAL-International Review of Applied Linguistics in Language Teaching, 44(3), 251-263.

Zampini, M. L. (1998). The relationship between the production and the perception of L2 Spanish stops. Texas papers in foreign language education, 3(3), 85-100.

Zampini, M. L. (2014). Voice onset time in second language Spanish. The handbook of Spanish second language acquisition (pp. 111-129). Wiley.

Zyzik, E. (2016). Toward a prototype model of the Heritage Language Learner. In M. Fairclough \& S. M. Beaudrie (Eds.), Innovative strategies for heritage language teaching: A practical guide for the classroom (pp. 19-38). Georgetown University Press.

\section{APPENDIX A: QUESTIONS FROM THE FOLLOW-UP INTERVIEW.}

\section{In Spanish:}

- ¿Qué lengua usas más en tu vida? ¿El inglés o el español?

o ¿Te identificas más con alguna de esas lenguas o te identificas con las dos por igual?

- ¿Cómo es la pronunciación de las palabras en inglés y español? ¿Es similar o diferente? ¿Cómo crees que es similar/ diferente?

o ¿Cuáles son algunas diferencias en la pronunciación que has notado entre las dos lenguas?

- ¿Has tomado el curso X en el departamento X de la universidad?

- ¿Te explicó alguien (un profesor/ una profesora, otra persona...) cómo es la pronunciación del español y el inglés?

o ¿Es importante o no es importante pronunciar de forma diferente en inglés y en español? ¿Por qué? 
- Cuando hablas en español y hay una palabra que se puede pronunciar de una forma similar en inglés y en español -como por ejemplo, parque¿cómo la pronuncias?

- Cuando hablas en inglés y hay una palabra que se puede pronunciar de una forma similar en inglés y en español -como por ejemplo, talent- ¿cómo la pronuncias?

- Cuando hay palabras que se escriben igual en las dos lenguas -como por ejemplo, Internet-, ¿ ¿cómo las pronuncias?

o ¿Crees que hay distintas formas de pronunciar esta palabra en inglés y en español o se pronuncian igual?

o Si se pronuncian de forma diferente, ¿cuándo se usa cada pronunciación?

- Cuando ves palabras como CD o DVD, ¿cómo las pronuncias si estás hablando en inglés? ¿y si estás hablando en español? ¿y si estás hablando con personas que sólo hablan español?

- ¿Qué es el Spanglish?

o ¿Qué opinas del Spanglish?

o ¿Está bien, está mal o da igual que la gente lo use?

o ¿Hay momentos en los que usas el español y el inglés en la misma frase o no?

$\square$ ¿Cuándo y con quién usas las dos lenguas en la misma frase?

$\square$ ¿Cuáles son las reacciones de la gente? ¿Te dicen algo, les da igual, ellos también lo hacen...?

In English:

- Which language do you use more in your life? Spanish or English?

$\square$ Do you identify yourself more with one of those languages or do you identify equally with both languages?

- How is the pronunciation of words in Spanish and English like? Is it similar or different? How do you think it is similar/ different?

What are some pronunciation differences that you have noted between the two languages?

- Have you taken the course $\mathrm{X}$ at the Department $\mathrm{X}$ at the university? ${ }^{3}$

\footnotetext{
${ }^{3}$ This question was included to know whether informants had taken courses related to linguistics or not.
} 
- Has anyone (a professor/ teacher, another person...) explained to you how pronunciation is like in Spanish and English?

o Is it important to pronounce words differently in English and in Spanish or not? Why?

- When you speak Spanish and there is a word that you can pronounce similarly in English and Spanish -like the word 'park"4- how do you pronounce it?

- When you speak English and there is a word that you can pronounce similarly in English and Spanish -like the word 'talent'- how do you pronounce it?

- When there are words that are written the same way in both languages like 'Internet'- how do you pronounce them?

o Do you think that there are different ways of pronouncing this word in English and in Spanish or are they pronounced the same?

o If they are pronounced differently, when do you use each pronunciation?

- When you see a word like CD or DVD, how do you pronounce it if you are speaking in English? And if you are speaking in Spanish? And if you are talking to people who only speak Spanish?

- What is Spanglish?

o What do you think of Spanglish?

o Is it good, bad, or you do not mind that people use it?

o Are there moments when you use Spanish and English in the same sentence or not?

$\square$ When and with whom do you use two languages in the same sentence?

What are people's reactions when you use two languages in the same sentence? Do they tell you something, they do not mind, or they also do it?

${ }^{4}$ The words in this question and in the following were presented using PowerPoint slides and they were not pronounced by the researcher conducting the interview. 